\title{
Squamous Cell Carcinoma Antigen Measurement
}

National Cancer Institute

\section{Source}

National Cancer Institute. Squamous Cell Carcinoma Antigen Measurement. NCI

Thesaurus. Code C120660.

The determination of the squamous cell carcinoma antigen present in a sample. 